06;15

\title{
Структурообразование наносистем цинка при использовании мембран АОА
}

\author{
(C) А.С. Корнющенко, В.И. Перекрестов, В.В. Наталич, И.В. Загайко
}

Сумский государственный университет, Сумы, Украина

E-mail: ganna.korniushchenko@fulbrightmail.org

Поступило в Редакцию 26 сентября 2016 г.

Предложен способ получения наносистем Zn при конденсации слабопересыщенных паров на систему мембрана анодно-окисленного алюминия (АОА) подложка $(\mathrm{Si})$. Для эффективного проникновения паров $\mathrm{Zn}$ в глубь пор AOA параллельно образующим пор формировался направленный паровой поток, при этом температура внешней поверхности мембраны была выше температуры подложки. Слабые паровые потоки получены при магнетронном распылении $\mathrm{Zn}$ в высокочистой инертной среде. Определены оптимальные условия формирования наносистем $\mathrm{Zn}$ в виде массива упорядоченных островков на поверхности подложки и связанных нанонитей на поверхности мембраны.

DOI: 10.21883/PJTF.2017.04.44303.16485

Упорядоченные массивы наноостровков металлов и полупроводников привлекают значительный научный интерес благодаря перспективам их использования в электронике, оптоэлектронике, сенсорах, ультратонких мониторах, устройствах хранения информации высокой плотности $[1,2]$. Различные наносистемы металлов обычно получают используя наношаблоны в виде мембран анодно-окисленного алюминия (AОА) [3-5], электронно-лучевую литографию [6-8] и процессы самоорганизации $[9,10]$. Важно подчеркнуть, что для реализации шаблонного метода с применением мембран АОА обычно используется электролитическое осаждение [4,5]. Необходимым условием реализации электролитического осаждения является достаточная для этого электропроводность подложек. Следовательно, спектр применяемых при этом подложек имеет определенные ограничения.

В отличие от электролитического осаждения для формирования упорядоченных массивов наноостровков Zn нами предложен более универсальный метод конденсации вещества вблизи термодинамического равновесия на систему мембрана АOA - подложка. При этом 
проводимость подложек не имеет значения, а для эффективного формирования наносистем шаблонным методом на поверхности подложки создавали узконаправленный паровой поток в глубь пор, а также поддерживали более высоким пересыщение паров над поверхностью подложки по сравнению с пересыщением над внешней поверхностью мембраны. Такой подход позволяет формировать наносистемы на любых подложках.

Некоторые особенности самоорганизации низкоразмерных систем при конденсации слабо пересыщенных паров нами рассмотрены в [11-14]. В этой связи определенный интерес представляют характерные особенности формирования наносистем $\mathrm{Zn}$ непосредственно на внешней поверхности мембраны АОА при условии предельно слабых пересыщений осаждаемых паров. Выбор Zn в качестве объекта исследования обусловлен тем, что после относительно простой методики окисления можно получить наносистемы $\mathrm{ZnO}$, которые имеют широкий спектр применений.

Таким образом, основная цель работы заключается в изучении механизмов структурообразования наносистем $\mathrm{Zn}$ на поверхности подложки из $\mathrm{Si}$ и на внешней поверхности мембран АОА при конденсации слабо пересыщенных паров на систему мембрана (AOA) - подложка $(\mathrm{Si})$, a также при условии более низких температур поверхности подложки по сравнению с внешней поверхностью мембраны.

Конденсация вещества в условиях, близких к равновесным, возможна при незначительном превышении текущего давления осаждаемых паров $P$ над равновесным давлением $P_{0}$. Поскольку равновесное давление $P_{0} \propto \exp \left(-E_{d} /\left(k_{b} T_{c}\right)\right)$ [15], получение близких к равновесным условий конденсации возможно при относительно высоких температурах ростовой поверхности $T_{c}$ и малых значениях энергии десорбции адатомов $E_{d}$. При этом даже незначительный перепад температур на различных участках ростовой поверхности может определить существенное различие скорости наращивания конденсата, что является основой предложенного нами технологического подхода.

Очевидно малые значения давлений осаждаемых паров $P$ можно обеспечить формированием предельно слабых стационарных осаждаемых потоков. В свою очередь малые скорости осаждения повышают вероятность образования конденсатов, имеющих примесные фазы, что может оказывать влияние на процесс структурообразования наносистем. По этим причинам для получения беспримесных конденсатов $\mathrm{Zn}$

Письма в ЖТФ, 2017, том 43, вып. 4 


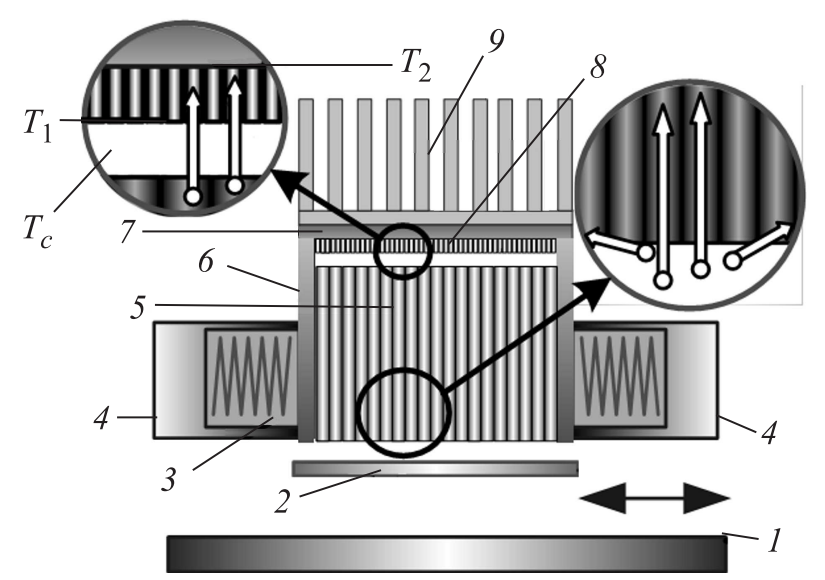

Рис. 1. Сечение устройства для получения наносистем $\operatorname{Zn}(1-$ мишень из $\mathrm{Zn}$ для магнетронного распылителя, 2 - заслонка, 3 - нагреватель на базе галогенных ламп, 4 - корпус нагревателя, 5 - система трубок, 6 - медный цилиндр, 7 - подложка, 8 - мембрана, 9 - радиатор охлаждения).

воспользовались вакуумной камерой, которая снабжена тремя несбалансированными магнетронными распылителями. Два из них применялись для очистки рабочего газа (Ar) от химически активных газов с помощью распыления титана [16]. При этом проводился беспроточный напуск Ar, а после его очистки парциальное давление всех остаточных химически активных газов составляло величину $8 \cdot 10^{-8} \mathrm{~Pa}[16]$. Третий магнетронный распылитель изолировался от двух других системой экранов и использовался для получения конденсатов $\mathrm{Zn}$.

Известно, что распределение по направлениям скоростей распыленных магнетроном атомов обычно имеет косинусоидальный характер [17]. Учитывая относительно большую площадь зоны распыления мишени, можно говорить о том, что распыленные атомы при приближении к порам AOА имеют широкий спектр направлений. Это в свою очередь может вызвать зарастание входных отверстий пор осаждаемым веществом, что в дальнейшем препятствует формированию упорядоченных наносистем на подложках по принципу шаблонного метода. Для решения этой проблемы воспользовались разработанным нами устройством [18], которое позволяет формировать узконаправленный поток

Письма в ЖТФ, 2017, том 43, вып. 4 


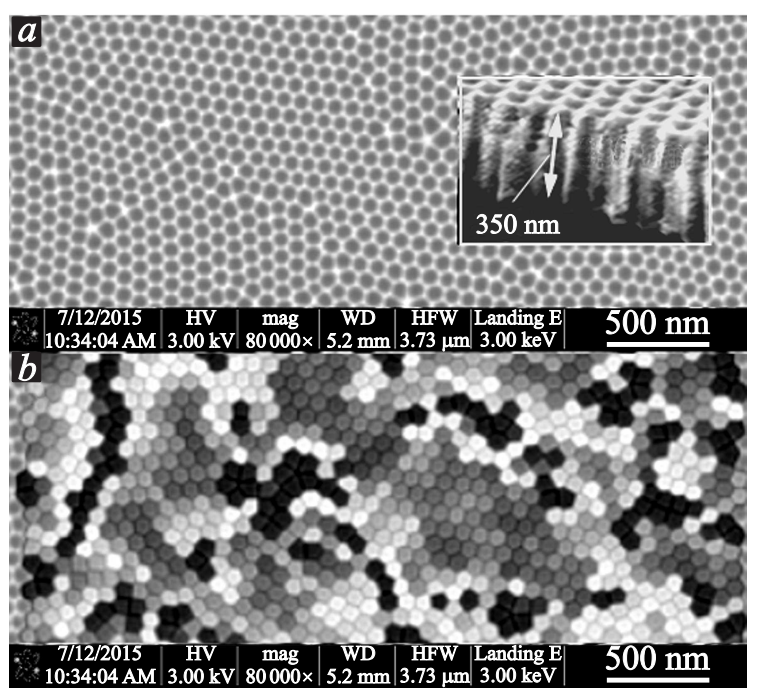

Рис. 2. Изображения пор анодно-окисленного алюминия в виде мембраны до $(a)$ и после $(b)$ обработки изображения с помощью специальной программы.

распыленных магнетроном атомов. На рис. 1 схематически изображено сечение этого устройства с мишенью магнетронного распылителя. Важным элементом устройства является система плотно прилегающих друг к другу тонкостенных медных трубок диаметром $\sim 2 \mathrm{~mm}$. Оси этих трубок ориентированы параллельно образующим пор АОА. Основное функциональное предназначение системы трубок 5 заключается в прохождении через них только тех распыленных атомов, направление движения которых ориентировано параллельно образующим пор АОА. При этом эффективность формирования узконаправленного потока распыленных атомов внутрь пор наиболее высока при соизмеримости длины свободного пробега атомов с расстоянием мишень 1 - подложка 7.

Минимизировать нежелательное зарастание входных отверстий пор конденсатом Zn можно также более интенсивным разогревом этой части поверхности. Для этого поверхность подложки, которая непосредственно контактирует с поверхностью мембраны, имела более низкую температуру $T_{2}$, чем температура внешней поверхности мембраны $T_{1}$

7 Письма в ЖТФ, 2017, том 43, вып. 4 
(рис. 1). Условие $T_{1}>T_{2}$ реализовано за счет радиатора охлаждения подложки 9 и разогрева внешней поверхности мембраны нагревателем 3. При этом для равномерного разогрева системы трубок 5 и внешней поверхности мембраны последние размещены во внутренней части медного цилиндра 6.

Для изучения морфологии конденсатов $\mathrm{Zn}$ и геометрических характеристик мембран AОА использовался растровый электронный микроскоп FEI NanoSEM 230.

На рис. 2, а показано электронно-микроскопическое изображение ультратонкой мембраны АОА. Мембрана состоит из областей, в пределах которых выполняется строгий порядок в расположении пор. При этом на границах этих областей симметрия в раположении пор нарушается. Для повышения информативности относительно однородности полученных структур проведена обработка изображения с помощью специальной программы. Области изображения с одинаковой степенью почернения соответствуют типу пор, ряды которых ориентированы в одном направлении (рис. 2, $b$ ).

В зависимости от технологических параметров приготовления диаметр отверстий в мембранах составлял величину $55-95 \mathrm{~nm}$, а их толщина варьировалась в пределах от 350 до $400 \mathrm{~nm}$.

Прежде всего, расчеты на основании методики [17] показали, что при давлении рабочего газа $P_{\mathrm{Ar}}<2.2 \mathrm{~Pa}$ длина свободного пробега распыленных атомов Zn превышает расстояние мишень-подложка $(\sim 90 \mathrm{~mm})$. Поскольку при $P_{\mathrm{Ar}}<0.8$ Ра стационарность работы магнетронных распылителей снижается, эффективное формирование узконаправленного потока распыленных атомов $\mathrm{Zn}$ внутрь пор AOA будет наблюдаться при $P_{\mathrm{Ar}} \sim 0.8-2.2 \mathrm{~Pa}$.

Следующая не менее важная задача заключалась в определении температуры конденсации и мощности разряда магнетронного распылителя цинка $P_{w}$, при которых в основном формируются наносистемы $\mathrm{Zn}$ на подложке из $\mathrm{Si}$, а не на внешней поверхности мембраны. Следует отметить, что строгое определение температур $T_{1}$ и $T_{2}$ (рис. 1 ) является весьма сложной задачей. В этой связи мы при помощи термопар определяли температуру $T_{c}$ в зазоре между системой трубок 5 и мембраной 8 , которая приблизительно соответствовала температуре $T_{1}$ (рис. 1). При этом установлено, что изменение $T_{c}$ от 35 до $150^{\circ} \mathrm{C}$ приводит к изменению температуры радиатора охлаждения 9 в пределах от 30 до $65^{\circ} \mathrm{C}$.

Письма в ЖТФ, 2017, том 43, вып. 4 


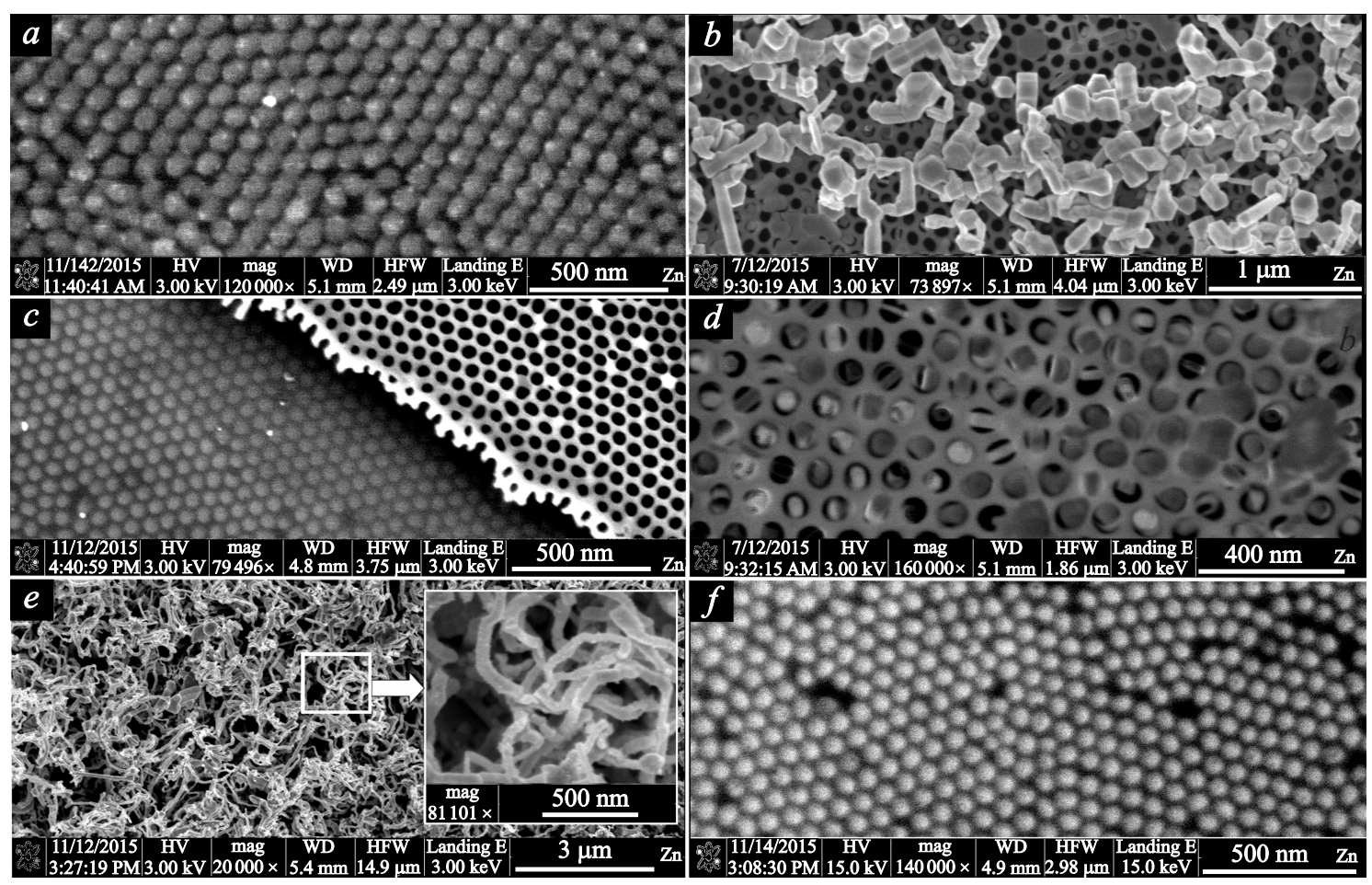

Рис. 3. Структура наносистем $\mathrm{Zn}$, сформированных на поверхности подложки из $\mathrm{Si}$ или внутри пор мембраны $(a, c, d, f)$, а также на поверхности мембраны $\mathrm{AOA}(b, e): a-T_{c} \sim 35-70^{\circ} \mathrm{C}, t_{c} \sim 0.4-0.6 \mathrm{~h} ; b-T_{c} \sim 35-70^{\circ} \mathrm{C}$, $t_{c} \sim 0.4-0.6 \mathrm{~h} ; c-T_{c}=150^{\circ} \mathrm{C}, t_{c}=0.6 \mathrm{~h} ; d-T_{c}=150^{\circ} \mathrm{C}, t_{c}=0.9 \mathrm{~h} ; e-T_{c}=150^{\circ} \mathrm{C}, t_{c}=1.6 \mathrm{~h} ; f-$ $T_{c} \sim 35-70^{\circ} \mathrm{C}, t_{c} \sim 0.4-0.6 \mathrm{~h}$. 
Рассмотрим закономерность структурообразования упорядоченных наносистем $\mathrm{Zn}$ при различных значениях $T_{c}$, а также при $P_{\mathrm{Ar}} \sim 1.5 \mathrm{~Pa}$ и мощности разряда магнетронного распылителя $12 \mathrm{~W}$. На основе исследований структурно-морфологических характеристик полученных наносистем цинка нами установлено, что при относительно низких значениях $T_{c}\left(35-70^{\circ} \mathrm{C}\right)$ на подложке из $\mathrm{Si}$ формируется упорядоченная система островков $\mathrm{Zn}$ (рис. 3,a). Наряду с этим, как показали РЕМ-исследования, на внешней поверхности мембран при $T_{c} \sim 35-70^{\circ} \mathrm{C}$ также наблюдается образование пористой структуры $\mathrm{Zn}$ (рис. $3, b$ ). Необходимо отметить, что первые признаки формирования пористых систем на поверхности мембраны наблюдается по истечении времени конденсации $t_{c} \sim 0.4-0.6 \mathrm{~h}$. Наряду с этим при относительно высоких значениях $T_{c}\left(\sim 150^{\circ} \mathrm{C}\right)$ и времени осаждения $\sim 0.6 \mathrm{~h}$ рост пористых образований на поверхности мембраны не наблюдается (рис. $3, c$ ). При этом нами установлено, что при $T_{c} \sim 150^{\circ} \mathrm{C}$ можно получить конденсаты исключительно внутри пор даже при времени осаждения $0.9 \mathrm{~h}$ (рис. $3, d$ ). Однако в этом случае поры заполнены конденсатом $\mathrm{Zn}$ с различной степенью, а при более продолжительной конденсации $\left(t_{c} \sim 1.6 \mathrm{~h}\right)$ на поверхности мембран формируются пористые структуры в виде трехмерных сетей из нанонитей (рис. $3, e$ ).

Нами не установлено различие механизмов структурообразования наносистем $\mathrm{Zn}$ при использовании мембран с относительно большими $(0.9 \mathrm{~nm})$ и малыми $(0.55 \mathrm{~nm})$ диаметрами отверстий и прочих одинаковых технологических условий (рис. $3, a$ и $f$ ).

Таким образом, в работе предлагается универсальный технологический подход формирования упорядоченных массивов наноостровков и соединенных между собой нанонитей $\mathrm{Zn}$ при использовании околоравновесной конденсации паров на систему мембрана (АОА) -подложка $(\mathrm{Si})$.

\section{Список литературы}

[1] Lei Y., Cai W., Wilde G. // Prog. Mater Sci. 2007. V. 52. P. 465-539.

[2] Lei Y., Yang S., Wub M., Wilde G. // Chem. Soc. Rev. 2010. V. 40. P. 1247-1258.

[3] Shingubara S. // J. Nanopart. Res. 2003. V. 5. P. 17-30.

[4] Wu M., Wen L., Lei Y. et al. // Small. 2010. V. 6. P. 695-699.

[5] Huczko A. // Appl. Phys. A. 2000. V. 70. P. 365-376.

[6] Matsui S., Ochiai Y. // Nanotechnology. 1996. V. 7. P. 247-258.

Письма в ЖТФ, 2017, том 43, вып. 4 
[7] Chu W., Smith H.I., Schattenburg M.L. // Appl. Phys. Lett. 1991. V. 59. P. $1641-1643$.

[8] Lei Y., Jiao Z., Wu M., Wilde G. // Adv. Eng. Mater. 2007. V. 9. Iss. 5. P. 343-348.

[9] Puntes V.F., Krishnan K.M., Alivisatos A.P. // Science. 2001. V. 291. P. $2115-2117$.

[10] Whitesides G.M., Grzyboeski B.A. // Science. 2002. V. 295. P. 2418-2421.

[11] Perekrestov V.I., Kosminska Y.O., Kornyushchenko A.S., Latyshev V.M. I/ Physica B. 2013. V. 411. P. 140-148.

[12] Perekrestov V.I., Kornyushchenko A.S., Kosminskaya Y.A. // Tech. Phys. 2008. V. 53. P. 1364-1370.

[13] Perekrestov V.I., Kornyushchenko A.S., Natalich V.V. // Solid State Sci. 2014. V. 33. P. 12-18.

[14] Perekrestov V.I., Kosminska Y.O., Kornyushchenko A.S., Mokrenko A.A. // J. Porous Mater. 2013. V. 20. P. 967-974.

[15] Maissel L.I., Glang R. Handbook of Thin Film Technology. V. 1. New York: Mc Graw Hill Hook Company, 1970. P. 1-170.

[16] Perekrestov V.I., Kravchenko S.N. // Instrum. Exp. Tech. 2002. V. 45. P. 404-407.

[17] Znamenskii A.G., Marchenko V.A. // Tech. Phys. 1998. V. 43. P. 766-773.

[18] Perekrestov V.I., Kornyushchenko A.S., Natalich V.V. et al. // Mater. Lett. 2015. V. 153. P. $171-174$.

[19] Mokrenko A.A., Perekrestov V.I., Kosminska Y.O. // J. Nano-Electron. Phys. 2010. V. 3. Iss. 2. P. 36-47.

Письма в ЖТФ, 2017, том 43, вып. 4 